\title{
DESIGN OF LEAD-LAG AND FUZZY LOGIC POWER SYSTEM STABILIZER USING PARTICLE SWARM OPTIMIZATION TECHNIQUE
}

\author{
Alaa-A, Khalil \\ Amany EL-Zonkoly \\ Naser M. Ahmied \\ Arab Academy For Science \& Technology, Faculty of Engineering, Egypt
}

\begin{abstract}
ABSTKACT
In this paper, a novel design method for optimal tuning of brushless exciter parameters using particle swarm optimization algorithm is presented. The problem of simultaneous and coordinated tuning of brushless exciter and lead-lag power system stabilizer parameters of a single infinite bus power system is considered. This problem is formulated as an optimization problem, which is solved using particle swarm optimization technique. Also in this paper, the optimal tuning of a fuzzy logic power system stabilizer using particle swarm optimization method is carnied out. Simulation results show the effectiveness of the proposed particle swarm optimization-based leadlag power system stabilizer and particle swarm optimization-based fuzzy logic power system stabilizer to damp the oscillation of multi machine system and work effectively under variable loading and fault conditions.
\end{abstract}

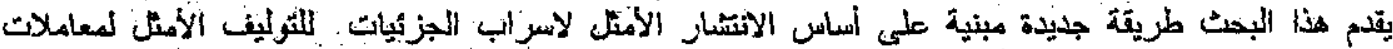

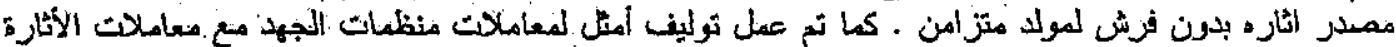

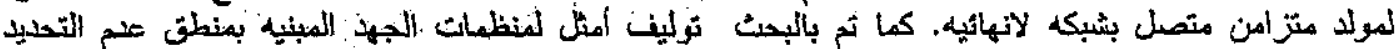

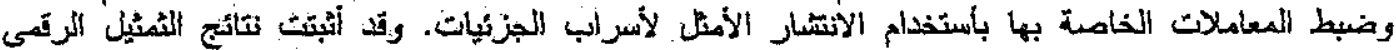

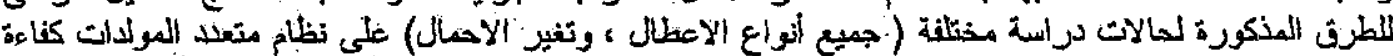

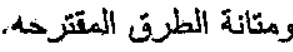

Keywiords: Particle swarm optimization, power system control, lead-lag power system stabilizer, and fuzzy logic power system stabilizer.

List of symbols

$\mathrm{E}_{\mathrm{B}}$ : the infinite bus voltage in pu.

$\mathrm{E}_{\mathrm{l}}$; the generator terminal voltage in $\mathrm{pu}$.

$\omega_{s}$ : the angular speed of the rotor in rad/s.

$\Psi_{\mathrm{fd}}$ : the field circuit flux linkage.

$\mathrm{L}_{\mathrm{fd}}:$ the field circuit inductance in $\mathrm{pu}$.

$\mathrm{R}_{\mathrm{fd}}$ : the field circuit resistance in $\mathrm{pu}$

H. : inertia constant in MW: S/MVA

$\omega_{0}$ : the rated rotor electrical speed in rad/s.

$X_{d}$ : direct axis reactance of the generator in $\mathrm{pu}$.

$X_{d}^{\prime}$ : the transient reactance of the generator in pu.

$X_{T q}$ : the total q-axis reactance of the system in pu.

$X_{\mathrm{Td}}$ : the total d-axis reactance of the system in pu.

$X_{L}$ : the generator leakage reactance in $\mathrm{pu}$.

$K_{s d}$ : the d-axis saturation coefficients

$\mathrm{K}_{\mathrm{sq}}$ : the $\mathrm{q}$-axis saturation coefficients.

$R_{T}$ : The total system resistance in pu.

$\mathrm{L}_{\text {adu }}$ : the generator $\mathrm{d}$-axis unsaturated value of the mutual inductance in pu.

$K_{D}$ : damping torquie coefficient in pu.

$\mathrm{K}_{\mathrm{s}}$ : Synchronizing torque coefficient in pu torque/rad. 


\section{INTRODUCTION}

Power systems are inherently nonlinear and undergo a wide range of transient conditions, which results in under damped low frequency speed as well as power oscillations that are difficult to control. The generator excitation system maintains generator voltage and controls the reactive power flow using an automatic voltage regulator (AVR)[1]. The role of an AVR is to hold the terminal voltage magnitude of a synchronous generator at a specified level. Hence, the stability of the AVR system would seriously affect the security of the power system. AVR helps to improve the steady-state stability of power systems, but transient stability became a concern for the power system operators. In transient stability the machine is subjected to large impact, usually a fault, which is maintained for a short time and cause a significant reduction in the machine terminal voltage and ability to transfer synchronizing power.

To enhance system damping, the generator is equipped with power system stabilizer (PSS) that provide supplementary feedback stabilizing signal in the excitation system [2]-[4]. A supplementary control signal in the excitation system and/or the governor system of a generating unit can be used to provide extra damping for the system and thus improve the dynamic performance. Power system stabilizers contribute in maintaining power system stability and improve dynamic performance by providing a supplementary signal to the excitation system. The problem of the PSS design is a multimodal optimization problem (i.e., there exists more than one local optimum). Hence, conventional optimization techniques are not suitable for such a problem. Moreover, there is no local criterion to decide whether a local solution is also the global solution. Therefore, conventional optimization methods that make use of derivatives and gradients, in general, not able to locate or identify the global optimum.

An overview of the research effort developed in the last decades and also on trends of small-signal studies in power system dynamic analysis are presented in [5]-[8] which discuss the modeling, control techniques and analysis tools available. Many random search methods, such as genetic algorithm (GA) and simulated annealing (SA) [9]-[10]. have recently received much interest for achieving high efficiency and search global optimal solution in problem space. The GA has parallel search techniques, which emulate natural genetic operations. Recently, heuristic search algorithms such as genetic algorithm [11],[12]. and simulated annealing [13] has been applied to the problem of PSS design.

In [13], authors propose a method that simultaneously optimizes both phase compensations and gain settings for the stabilizer using Genetic
Algorithms. Although GA is very sufficient in finding global or near global optimal solution of the problem, it requires a very long run time that may be several minutes or even several hours depending on the size of the system under study. Particle swarm optimization (PSO), first introduced by Kennedy and Eberhart, is one of the modern heuristic algorithms. It was developed through simulation of a simplified social system, and has been found to be robust in solving continuous nonlinear optimization problems [14]-[15]. The PSO technique can generate a high quality solution within shorter calculation time and stable convergence characteristic than other stochastic methods [16]. PSO has been motivated by the behavior of organisms, such as fish schooling and bird flocking. Generally, PSO is characterized as a simple concept, easy to implement, and computationally efficient. Unlike the other heuristic techniques, PSO has a flexible and well-balanced mechanism to enhance the global and local exploration abilities.

In this paper, the problem of simultaneous and coordinated tuning of brushless exciter and lead-lag power system stabilizer parameters of a single infinite bus power system is considered. Also the design of a fuzzy logic power system stabilizer using particle swarm optimization is carried out. Simulation results show the effectiveness of the proposed particle swarm optimization-based lead-lag power system stabilizer (PSOLLPSS) and particle swarm optimization-based fuzzy logic power system stabilizer (PSOFLPSS) to damp oscillation of multi machine system and work effectively under various loading and fault conditions.

\section{LINEARZED MODEL OF A SINGLE- MACHINE SYSTEM FOR SMALL-SIGNAL STABUITY}

The system considered for small-signal performance study is shown Fig.(1). The synchronous generator considered is equipped with brushless exciter (AC1A) and lead-lag power system stabilizer (LLPSS). The details of the power system with a thyristor exciter and type AC1A excitation system block diagram can be found in [6]. Synchronous generator is described by the following state space representation:

$$
\begin{aligned}
& \dot{x}=A x+b u \\
& y=c x+D u
\end{aligned}
$$

The complete state-space model, including the LLPSS, has the following form (with $\square T_{\mathrm{m}}=0$ ):

The matrices $A, B, C$ and $D$ are as follows

$$
\mathbf{x}^{\mathrm{T}}=\left[\Delta \omega_{\mathrm{r}} \Delta \delta \Delta \Psi_{\mathrm{fd}} \Delta \mathrm{v}_{1} \Delta \mathrm{v}_{2} \Delta \mathrm{v}_{\mathrm{s}}\right]
$$




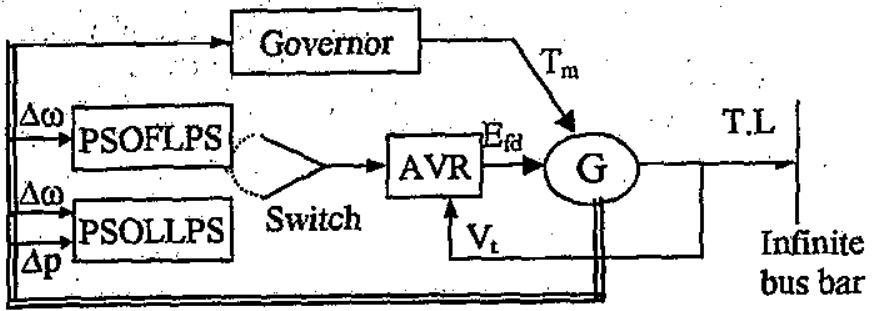

Fig. 1 schematic diagram for single machine-infinite bus

$$
A=\left[\begin{array}{cccccc}
a_{11} & a_{12} & a_{13} & 0 & 0 & 0 \\
a_{21} & 0 & 0 & 0 & 0 & 0 \\
0 & a_{32} & a_{33} & a_{34} & 0 & a_{36} \\
0 & a_{42} & a_{43} & a_{44} & 0 & 0 \\
a_{51} & a_{52} & a_{53} & 0 & a_{55} & 0 \\
a_{61} & a_{62} & a_{63} & 0 & a_{65} & a_{66}
\end{array}\right]
$$

$$
\begin{aligned}
& B^{T}=\left[\begin{array}{llllll}
0 & 0 & K_{A} b_{32} & 0 & 0 & 0
\end{array}\right] \\
& \mathrm{C}=\left[\begin{array}{llllll}
0 & 1 & 0 & 0 & 0 & 0
\end{array}\right] \\
& \mathrm{D}=[0]
\end{aligned}
$$

Where,

$$
\begin{aligned}
& a_{11}=-\frac{K_{D}}{2 H}, \quad a_{12}=-\frac{K_{1}}{2 H}, \\
& a_{13}=-\frac{K_{2}}{2 H}, \quad a_{21}=2 \pi f_{0}, \\
& m_{1}=\frac{E_{B}\left(X_{T q} \sin \delta_{0}-R_{T} \cos \delta_{0}\right)}{D} \\
& m_{2}=\frac{X_{T_{q}}}{D} \frac{L_{a d s}}{\left(L_{a d s}+L_{f d}\right)}, L_{a d s}=\frac{1}{1}+\frac{1}{L_{f d}} \\
& a_{33}=-\frac{a_{0} R_{f d}}{L_{f d}}\left[1-\frac{L_{a d s}}{L_{f d}}+m_{2} L_{a d s}\right], b_{11}=-\frac{1}{2 H}, \\
& b_{32}=-\frac{\omega_{0} R_{f d}}{L_{a d u}}, \quad a_{34}=-\frac{\omega_{0} R_{f d}}{L_{a d u}} K_{A}, \\
& a_{36}=-\frac{\omega_{0} R_{f d}}{L_{a d t u}} K_{A}, a_{42}=-\frac{K_{5}}{T_{R}}, a_{43}=-\frac{K_{6}}{T_{R}}, \\
& a_{44}=-\frac{1}{T_{R}}, \quad a_{51}=K_{S T A B} a_{11}, \quad a_{52}=K_{S T A B} a_{12}, \\
& a_{53}=K_{S T A B} a_{13}, a_{55}=-\frac{1}{T_{W}}, a_{61}=\frac{T_{1}}{T_{2}} a_{51}, \\
& a_{62}=\frac{T_{1}}{T_{2}} a_{52}, \quad a_{63}=\frac{T_{1}}{T_{2}} a_{53}, \quad a_{65}=\frac{T_{1}}{T_{2}} a_{55}+\frac{1}{T_{2}} \\
& a_{66}=\frac{1}{T_{2}}, \quad b_{3}=-\frac{\omega_{0} R_{f d}}{L_{a d u}} K_{A}
\end{aligned}
$$

The description of $K_{1}$ to $K_{6}$ and block diagram with exciter gain is shown in details in [6].

For excitation system type AClA exciter we need to calculate $\Delta_{f a}$

$$
\Delta_{f d}=K_{7} \Delta \psi_{f d}+K_{8} \Delta \delta
$$

Where

$$
K_{7}=\frac{1}{L_{f d}}\left[1-\frac{L_{a d s}^{\prime}}{L_{f d}}+m_{2} L_{a d s}^{\prime}\right], \quad K_{8}=\frac{1}{L_{f d}}\left[m_{1} L_{a d s}^{\prime}\right]
$$

\section{OVERVIEW OF PARTICLE SWARM OPTIMIZATION}

PSO is one of the optimization techniques and a kind of evolutionary computation technique. The method has been found to be robust in solving problems featuring nonlinearity and nondifferentiability, multiple optima, and high dimensionality through adaptation, which is derived from the socialpsychological theory. The features of the method are as follows: -

1. The method is developed from research on swarm such as fish schooling and bird flocking.

2. It is based on a simple concept. Therefore, the computation time is short and requires few memories [7].

3. It was originally developed for nonlinear optimization problems with continuous variables. It is easily expanded to treat a problem with discrete variables. According to the research results for birds flocking are finding food by flocking.

PSO is basically developed through simulation of bird flocking in two-dimension space. The position of each agent is represented by $\mathrm{XY}$ axis position and also the velocity is expressed by $v_{x}$ (the velocity of $X$ axis) and $v_{y}$ (the velocity of $Y$ axis). Modification of the agent position is realized by the position and velocity information. Bird flocking optimizes a certain objective function. Each agent knows its best value so far (pbest) and its $X Y$ position. This information is analogy of personal experiences of each agent. Moreover, each agent knows the best value so far in the group (gbest) among pbest. This information is analogy of knowledge of how the other agents around them have performed. Namely, each agent tries to modify its position using the following information: 
- The current positions $(x, y)$,

- The current velocities $\left(v_{x}, v_{y}\right)$,

- The distance between the current position and pbest

- The distance between the current position and gbest

This modification can be represented by the concept of velocity. Velocity of each agent can be modified by the following equation:

$v_{i}^{k+1}=w v_{i}^{k}+c_{1}$ rand $\times\left(\right.$ pbest $\left.-s_{i}^{k}\right)+c_{2}$ rand $\times\left(\right.$ gbest $\left.-s_{i}^{k}\right)$

Where,

$v_{i}^{k}$ : velocity of agent $\mathrm{i}$ at iteration $\mathrm{k}$,

$w$ : Weighting function,

$c_{t}$ : Weighting factor,

rand: random number between 0 and 1 ,

$s_{i}^{k}$ : Current position of agent $\mathrm{i}$ at iteration $\mathrm{k}$,

pbest : pbest of agent $i$,

gbest : gbest of the group

$$
w=-\frac{w_{\text {max }}-w_{\min }}{\text { ite }_{\max }} \times \text { iter }
$$

The following weighting function is usually utilized in (8)

$w_{\max }:$ Initial weight,

$w_{\min }$ : Final weight;

iter $_{\max }:$ Maximum iteration number,

iter : current iteration number,

Using equation (8) and (9) a certain velocity, which gradually gets close to pbest and gbest can be calculated. The current position can be modified by the following equation:

$$
s_{i}^{k+1}=s_{i}^{k}+v_{i}^{k+1}
$$

Figure (2) shows a concept of modification of searching point by PSO.

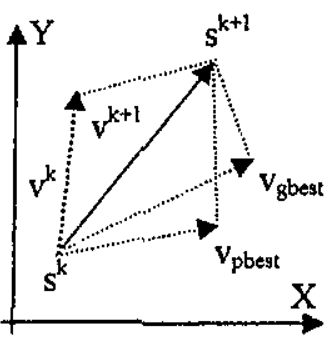

\section{Where}

$\mathbf{s}^{\mathrm{k}}$ : Current searching point, $\mathrm{s}^{\mathrm{k}+\mathrm{l}}$ : modified searching point $v^{k}$ : Current velocity, $v^{k+1}$ : modified velocity,

$V_{\text {pben: }}$ : velocity based on pbest $V_{\text {gien }}$ : velocity based on gbest

Fig. 2 concept of modification of searching point by PSO

\section{LEAD-LAG POWER SYSTEM STABILIZER}

The control parameters to be tuned through the optimization algorithm for exciter type (AClA) parameters (KA,TA,TB,TC) where $\mathrm{KA}$ and $\mathrm{TA}$ are the amplifier parameters; and TB and TC are the lead-lag compensator parameters. The lead-lag power system stabilizer consists of three block, a phase compensation of block which parameters are
(T1,T2), a signal washout which parameter TW and gain block (KSTAB) and terminal voltage transducer $\mathrm{TR}$, as shown in the Fig.(3).The inputs to the excitation system are the terminal voltage, reference voltage VR and the signal from the PSS output VS, the input to the PSS is the speed deviation $\Delta \omega$.We will investigate the performance of particle swarm optimization (PSO) technique proposed for tuning excitation system $(\mathrm{AClA})$ and lead-lag power system stabilizer parameters.

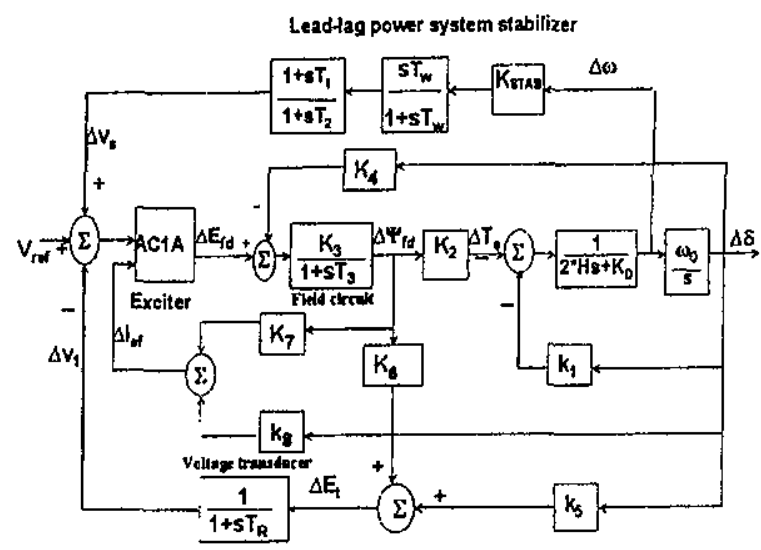

Fig. 3 block diagram representation a synchronous machine with a brushless exciter and LLPSS

For the linearzed system model presented the eigenvalues of the total system can be evaluated. The proposed method is aiming to search for the optimal parameters set of the AC1A exciter and the lead-lag power system stabilizer so that a comprehensive damping index (CDI) (objective function) can be minimized [17].

$$
\mathrm{O} F=\sum_{i=1}^{n}\left(1-\xi_{i}\right)
$$

where,

O.F : is objective function.

$\xi_{\mathrm{i}}:$ is the damping ratio.

$n:$ is the total number of the dominant eigenvalues.

The objective of the optimization is to maximize the damping ratio as much as possible. The computational flow chart of PSO algorithm is shown in Fig (4). The lower and upper bound of the exciter type (AC1A) and lead lag power system stabilizer parameters are given in Table (1).

According to the simulation, the following PSO parameters are used for verifying the performance of the PSOLLPSS in searching for the LLPSS and AClA parameters:

- The members of each individual is $\left(K_{A}, T_{A}, T_{B}, T_{C}, T_{1}, T_{2}, T_{W_{1}} K_{S T A B}, T_{R}\right)$.

- Population size $=50$;

- Inertia weight factor $w$ is set by Eq (9), where $w_{\max }=0.9$ and $w_{\min }=0.4$;

- Acceleration constant $c_{1}=2$ and $c_{2}=2$ 
The LLPSS and AC1A parameters that showed the best solution are summarized in Table (2).

\section{Start}

Specify the system parameters for PSO

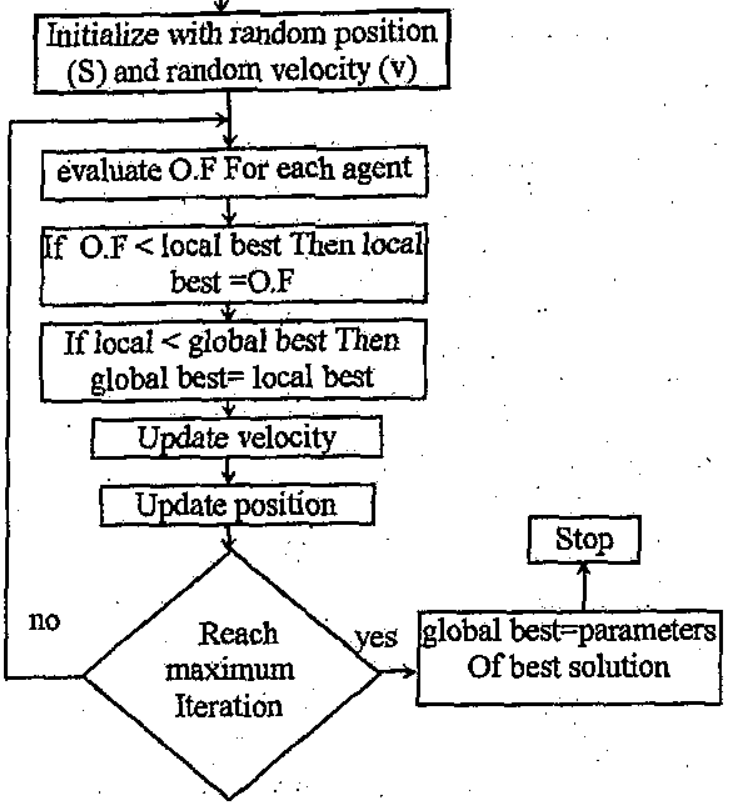

Fig. 4 Flowchart of particle swarm optimization process

Table (1) Lower and upper limits of control parameters:

\begin{tabular}{|c|c|c|c|c|c|c|c|c|c|}
\hline $\begin{array}{c}\text { Para- } \\
\text { meter }\end{array}$ & $\mathrm{K}_{\mathrm{A}}$ & $\mathrm{T}_{\mathrm{A}}$ & $\mathrm{T}_{\mathrm{B}}$ & $\mathrm{T}_{\mathrm{C}}$ & $\mathrm{K}_{\text {stab }}$ & $\mathrm{T}_{\mathrm{W}}$ & $\mathrm{T}_{1}$ & $\mathrm{~T}_{2}$ & $\mathrm{~T}_{\mathrm{R}}$ \\
\hline $\begin{array}{c}\text { Lower } \\
\text { Limit }\end{array}$ & 200 & 0.01 & 0.05 & 1 & 3 & 1 & 0.01 & .001 & 0.01 \\
\hline $\begin{array}{l}\text { Upper } \\
\text { Limit }\end{array}$ & 400 & 0.1 & 0.1 & 2 & 50 & 2 & 0.2 & .005 & 0.1 \\
\hline
\end{tabular}

Table (2) Optimal control parameters:

\begin{tabular}{|c|c|c|c|c|c|c|c|c|c|}
\hline $\begin{array}{c}\text { Para- } \\
\text { meter }\end{array}$ & $\mathrm{K}_{\mathrm{A}}$ & $\mathrm{T}_{A}$ & $\mathrm{~T}_{B}$ & $\mathrm{~T}_{\mathcal{E}}$ & $\mathrm{K}_{\text {sies }}$ & $\mathrm{T}_{\mathrm{W}}$ & $\mathrm{T}_{1}$ & $\mathrm{~T}_{2}$ & $\mathrm{~T}_{\mathrm{R}}$ \\
\hline Optimal & 200 & 0.1 & 0.1 & 1 & 50 & 2 & 0.2 & .005 & 0.1 \\
\hline
\end{tabular}

\section{FUZZY LOGIC-BASED POWER SYSTEM} STABILIZER

The main components of a typical fuzzy logic controller (FLC) include fuzzification, fuzzy inference engine (decision logic); and defuzzification stages. In this paper, power system model consisting of a synchronous machine connected to infinite bus through a transmission line is used in the simulation studies as show in Fig (1). The control signal generated by the fuzzy logic power system stabilizer (FLPSS) is injected as a supplementary stabilizing signal to the AVR summing point.

The goal of this application is to stabilize and improve the damping of the synchronous machine. Speed deviation $\Delta \omega$ and active power deviation $\Delta p$ have been selected as the controller inputs. The controller output is then injected into the AVR summing point.

This configuration implies that the FLC has two input parameters; $k_{w}$ and $k_{p}$ and one output parameter $\mathbf{k}_{u}$ as seen in Fig..(5). The selection of these parameters is usually subjective and requires previous knowledge of the fuzzy control variables (input and output signals).

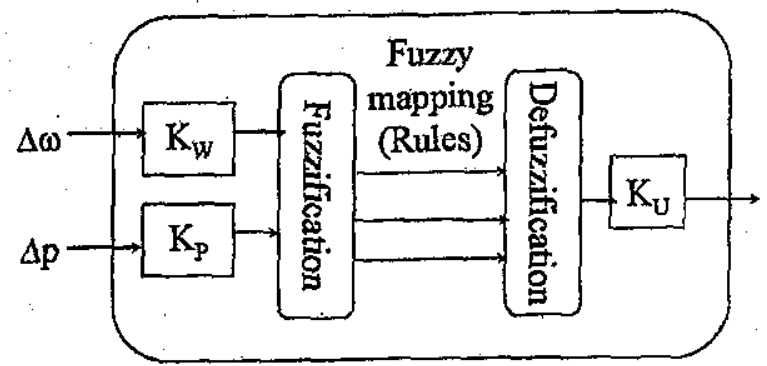

Fig. 5 Schematic diagram of the FLPSS

The active power $(\Delta \mathrm{p})$ and speed deviation $(\Delta \omega)$ these two inputs are fuzzified. The active power $(\Delta p)$ , speed deviation $(\Delta \omega)$ and the fuzzy ontput signal (U) are divided into seven triangular shape member ship functions with full range $[-1$ to 1$]$. The member ship functions are shown in Fig. (6).

(Ap)

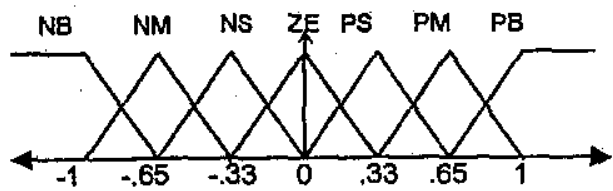

Input 1: Normalized membership function for active power

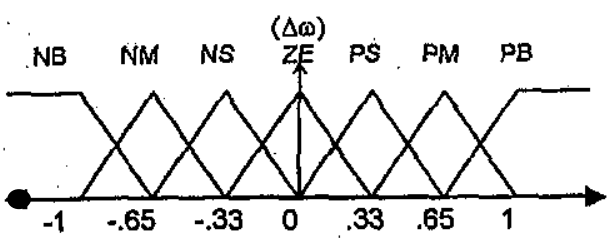

Input 2: Normalized membership function for speed deviation (U)

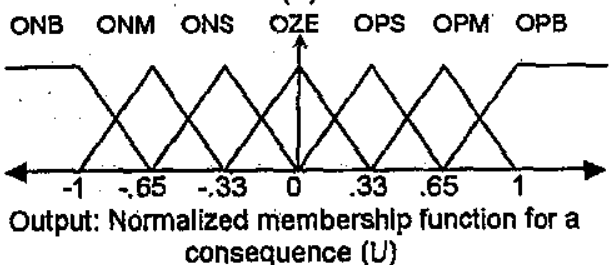

Fig. 6 Membership function of $(7 * 7)$ fuzzy controller

The member ship functions related to the speed deviation $(\Delta \omega)$, active power deviation $(\Delta \mathrm{p})$ are described by [Negative Big (NB), Negative Medium (NM), Negative small (NS), Zero (ZE), Positive Small (PS); Positive Medium (PM), Positive Big (PB)] and output signal (U) is described by [Output Negative Big (ONB), Output Negative 
Medium(ONM), output Negative Small (ONS), Output Zero (OZE), Output Positive Small (OPS), Output Positive Medium (OPM), Output Positive Big (OPB)]. Also previous experience of the controlled system dynamics is commonly used in the design of the fuzzy control rule base as shown in Table (3).

Table (3) Rule Base Table for the FLPSSS

\begin{tabular}{|c|c|c|c|c|c|c|c|}
\hline & NB & NM & NS & ZE & PS & PM & PB \\
\hline NB & ONB & ONB & ONB & ONB & ONS & ONS & OZE \\
\hline NM & ONB & ONB & ONM & ONM & ONS & OZE & OPS \\
\hline NS & ONB & ONM & ONM & ONS & OZE & OPS & OPM \\
\hline ZE & ONM & ONM & ONS & OZE & OPS & OPM & OPM \\
\hline PS & ONM & ONS & OZE & OPS & OPM & OPM & OPB \\
\hline PM & ONS & OZE & OPS & OPM & OPM & OPB & OPB \\
\hline PB & OZE & OPS & OPM & OPB & OPM & OPB & OPB \\
\hline
\end{tabular}

\section{FLPSS PARAMETER TUNING USING PSO}

Parameter tuning for the FLPSS plays an important role in achieving the controller goals. Previous experience of the controlled system is helpful in selection the initial values of the FLPSS parameters. If sufficient information is not available about the controlled system, the selection of suitable FLPSS parameters can become a tedious trial-and-error process. Some efforts have been reported in the literature to automate the tuning of the FLPSS parameters at the design stage to get an optimal or near optimal system performance [18].

In case of a complete lack of information about the parameters, the search for the best parameters may require a large number of iterations in searching for a proper minimum. Using some practical information about signal levels, it is easy to set an operating range to the FLPSS parameters.

The PSO method is an excellent optimization methodology and a promising approach for solving the optimal FLPSS parameters problem; Therefore, this study develops the Particle swarm optimizationbased fuzzy logic power system stabilize (PSOFLPSS).

The role of an AVR is to hold the terminal voltage magnitude of a synchronous generator at a specified level. Hence, the stability of the AVR system would seriously affect the security of the power system. The PSO tuning algorithm tries to minimize three system performance indices (PIs). These indices are the system overshoot (OS) and the performance indices $\mathrm{J}_{1}, \mathrm{~J}_{2}$, given as:

$$
\begin{aligned}
\text { OS } & =\left[\frac{\mathrm{r}-\mathrm{y}}{\mathrm{r}}\right]^{* 100 \%} \\
\mathrm{~J}_{1} & =\sum \mathrm{e}^{2} \\
\mathrm{~J}_{2} & =\sum \mathrm{te}^{2}
\end{aligned}
$$

Where, $I$ is the system reference, $y$ is the system output, $\mathrm{e}$ is the system error, and $\mathrm{t}$ is the time as show in Fig (7). A FLPSS has two input parameters $k_{w}, k_{p}$ and one output parameter $k_{u}$. These parameters can be tuned using PSO algorithm which changes the three parameters in overlap loops, and calculates the performance index. The algorithm also detects if one of the parameters degrades the performance indices or leads to instability. The tuning algorithm tries to minimize three system PIS by varying the FLPSS parameter [18].

\section{IMPLEMENTATION OF PSOFLPSS}

The PSO algorithm was mainly utilized to determine the optimal values of three optimal parameters $k_{w}, k_{p}$ and $\mathrm{k}_{\mathrm{u}}$, such that the controlled system could obtain a good output response.

We defined three FLPSS parameters $k_{w}, k_{p}$ and $k_{u}$, to compose an individual $\mathrm{K}$.

It is worth mentioning that the FLPSS is designed to minimize the power system oscillation after a disturbance so as to improve the stability.

These oscillations are expressed by adding the three system performance indices $\mathrm{PI}_{\mathrm{s}}$.

Where

$$
W(K)=J_{1}+J_{2}+O S
$$

\section{$\mathrm{W}(\mathrm{K})$ is performance criterion}

$\mathrm{K}$ is $\left[\mathrm{k}_{\mathrm{w}}, \mathrm{k}_{\mathrm{p}}, \mathrm{k}_{\mathrm{u}}\right]$

In the present study the objective function (O.F) is formulated as the minimization of:

$$
\operatorname{mim} \quad \mathrm{O} . \mathrm{F}=\mathrm{abs}(\mathrm{W}(\mathrm{K}))
$$

With the variation of the parameter $\mathrm{K}$ the O.F will also be changed. It aimed to mininize this objective function in order to improve the system response in terms of the settling time and overshoots.

The computational flow chart of PSO algorithm is shown in Fig (4).

The lower and upper limits of the three controller parameters are given in Table (4).

Table (4) lower and upper control parameters:

\begin{tabular}{|c|c|c|c|}
\hline Parameter & $\mathrm{k}_{\mathrm{w}}$ & $\mathrm{k}_{\mathrm{p}}$ & $\mathrm{k}_{\mathrm{u}}$ \\
\hline Lower limit & 40 & 4 & $\mathrm{l}$ \\
\hline Upper limit & 60 & 8 & 4 \\
\hline
\end{tabular}

According to the simulation, the following PSO parameters are used for verifying the performance of the PSOFLPSS controller in searching for the FLPSS controller parameters:

- The member of each individual are $k_{w}, k_{p}$ and $\mathrm{k}_{\mathrm{u}}$;

- Population size $=50$;

- Inertia weight factor $w$ is set by $\mathrm{Eq}(9)$ here $w_{\max }=0.9$ and $w_{\min }=0.4$

- Acceleration constant $c_{1}=2$ and $c_{2}=2$

The system with FLPSS and AC1A exciter is shown in Fig (7) that showed the best solution are summarized in Table (5). 
Table (5) optimal control parameters:

\begin{tabular}{|c|c|c|c|}
\hline Parameter & $\mathbf{k}_{\mathrm{w}}$ & $\mathrm{kp}$ & $\mathbf{k}_{\mathrm{u}}$ \\
\hline Optimal & 59.8 & 4 & 1 \\
\hline
\end{tabular}

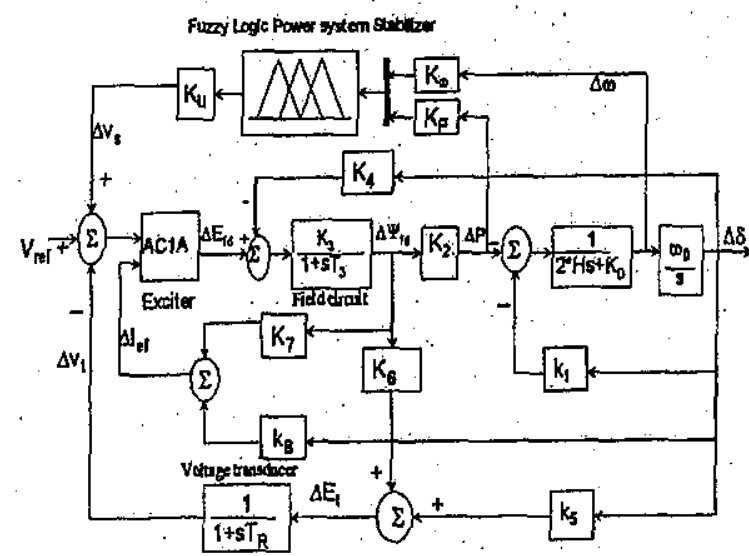

Fig. 7 block diagram representation a synchronous machine with a brushless exciter and FLPSS

\section{SIMULATION RESULTS}

In this section a single-machine-infinite bus system and a multi-machine infinite bus system will be tested after equipped by the proposed PSOLLPSS and PSOFLPSS. A comparison af the system responses will be done.

\subsection{Single-machine infinite bus model}

In the simulation of the single machine infinite bus system the synchronous machine considered is equipped with brushless excitation (AC1A) system and tested by a unit-step input signal (reference voltage $V_{R}=1$ ). The control signal generated by the PSOPSS (PSOLLPSS or PSOFLPSS) is injected as a supplementary stabilizing signial to AVR loop as shown in Fig (1). Fig. (8) shows the step response of with the speed deviation of a single machine power system with different control techniques PSOLLPSS and PSOFLPSS. The response of speed deviation $(\Delta \omega)$ with the PSOFLPSS and PSOLLPSS is nearly the same.

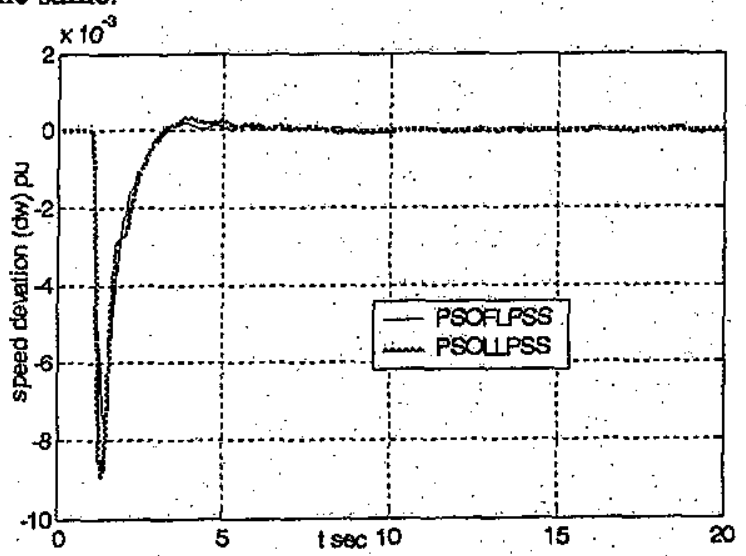

Fig. 8 speed deviation step response of a single machine power system with different (PSOPSS)
The time response of the terminal voltage $\left(V_{t}\right)$ of the PSOFLPSS is better than the response of the PSOLLPSS (less over shoot and time settling) as shown in Fig (9).

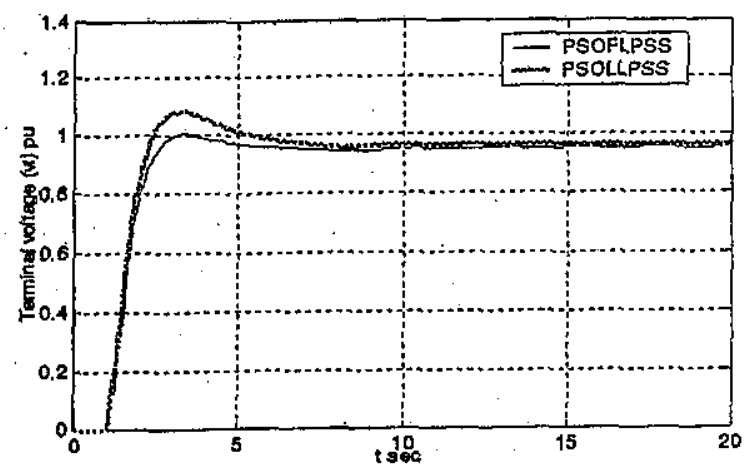

Fig. 9 Terminal voltage step response of a single machine power system with different (PSOPSS)

\subsection{Multi -machine infinite bus model}

In this study, a two area interconnected four machine power system shown in Fig.(10) is considered. The system consists of four machines arranged in two areas inter-connected by a weak tie line. The parameters for all generating units, transmission lines, load, and operating conditions are given in [6]. The system is operating with area 1 exporting 400 MW to area 2. The simulation has been done with the AC1A exciter, and LLPSS; or FLPSS used in the preceding single machine system in the model of Generator 1 (G1) in area 1. The power system stabilizers (PSOLLPSS, PSOFLPSS) are tested in the following cases:

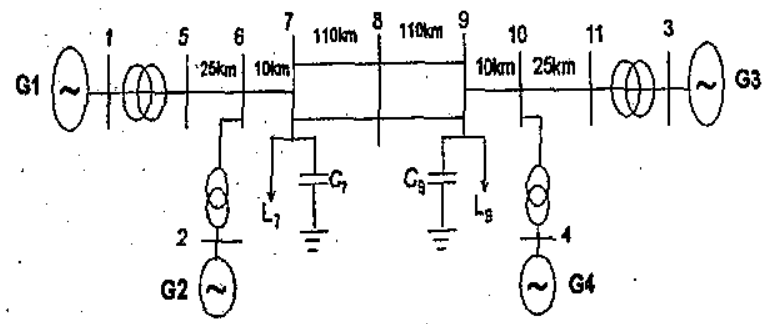

Fig. 10 Multi-machine power system

Single phase-to ground fault, double phase-to-ground fault, three phase-to-ground, one line out of service, load change $(+20 \%)$ at time $(10-15) \mathrm{sec}$ in the mid point of one of the two transmission lines (at bus 8) The location of the fault is indicated on Fig (10). All simulation results represent the system time response cases pre fault at time (0-10) sec, during fault at time $(10-15)$ see and post fault at time (15-25) sec. We will make a comparative study between PSOFLPSS and PSOLLPSS for different post fault condition.

\section{A. Single phase-to-ground fault}

The response of the speed deviation $(\Delta \omega)$ of the PSOLLPSS is better than response PSOFLPSS (less 
under shoot and settling time) as shown in the Fig (11).

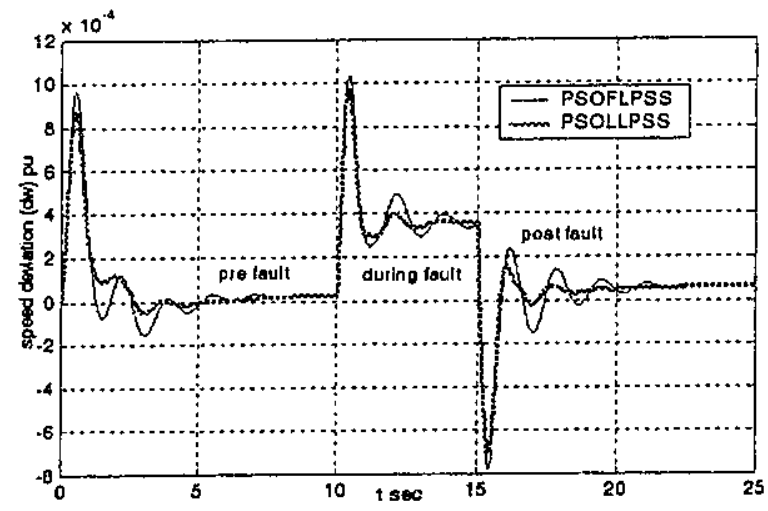

Fig. 11 comparison between PSOLLPSS and PSOFLPSS of machine (1) time Response single phase-to-ground fault

The time response of terminal voltage $(\mathrm{Vt})$ of PSOFLPSS is better than PSOLLPSS (less over shoot) and setting time nearly the same as shown in Fig (12).

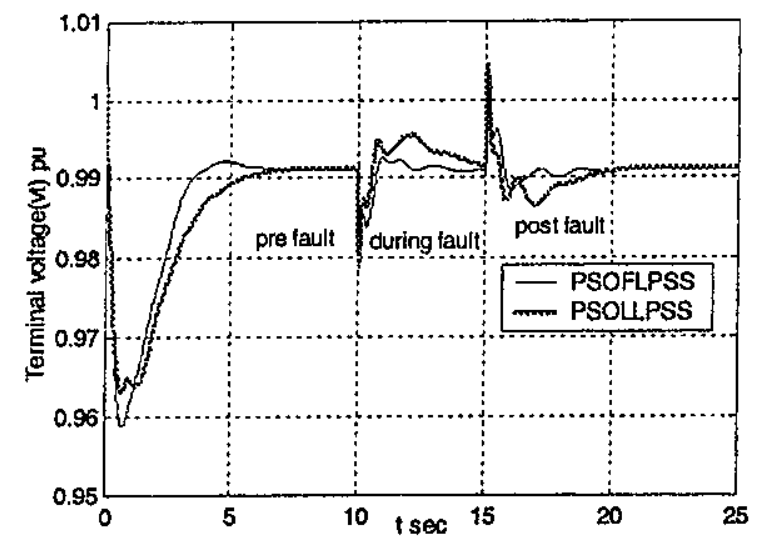

Fig. 12 comparison between PSOLLPSS and PSOFLPSS of machine (1) for a single phase-toground fault

\section{B. Double phase-to ground fault}

The time response of the speed deviation $(\Delta \omega)$ of PSOLLPSS is better than the response PSOFLPSS (less under shoot and less settling time) as show in the Fig (13). Also in the Fig (14) the terminal voltage (Vt) time response of PSOFLPSS is better than PSOFLPSS (less under shoot) and settling time nearly the same.

\section{Three phase-to ground fault}

The speed deviation $(\Delta \omega)$ time response of the PSOLLPSS is better than PSOFLPSS (less under shoot and settling time) as shown the Fig. (15). The terminal voltage $(\mathrm{Vt})$ time response of PSOLLPSS is better than PSOFLPSS (less over shoot and settling time) as shown in the Fig. (16).

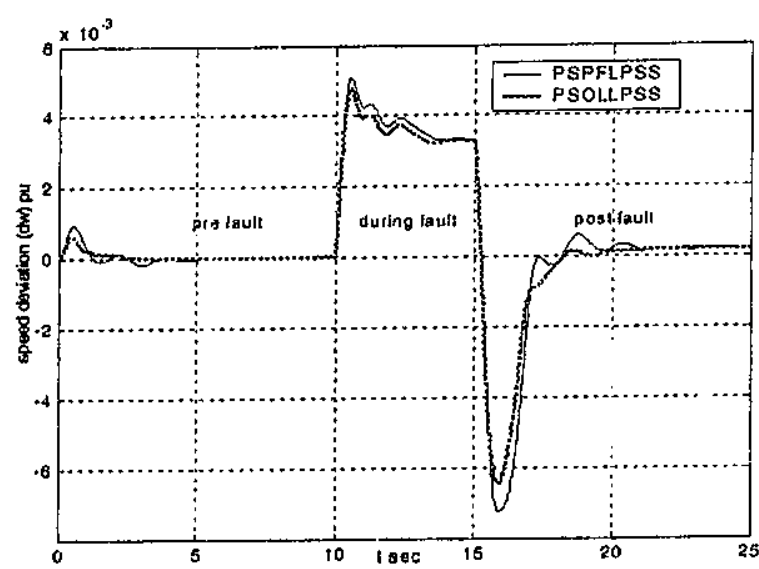

Fig. 13 comparison between PSOLLPSS and PSOFLPSS of machine (1) for a double phase-toground fault

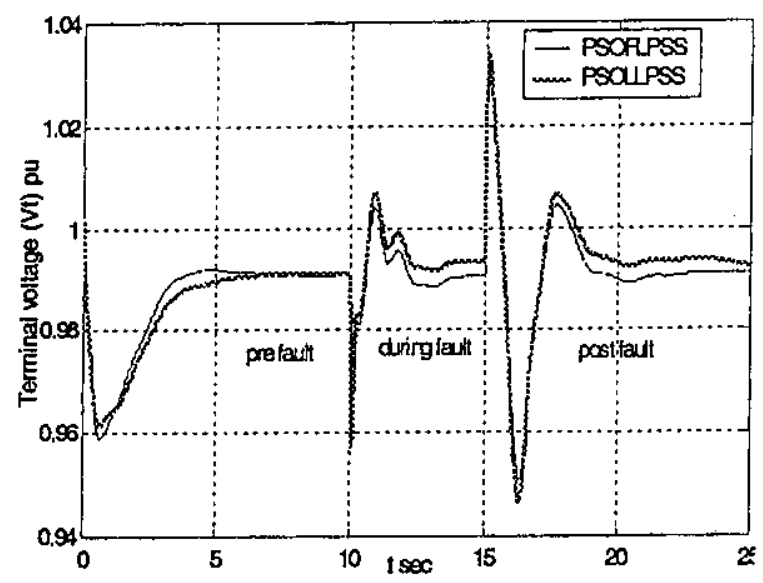

Fig. 14 comparison between PSOLLPSS and PSOFLPSS of machine (1) for a double phase-toground fault

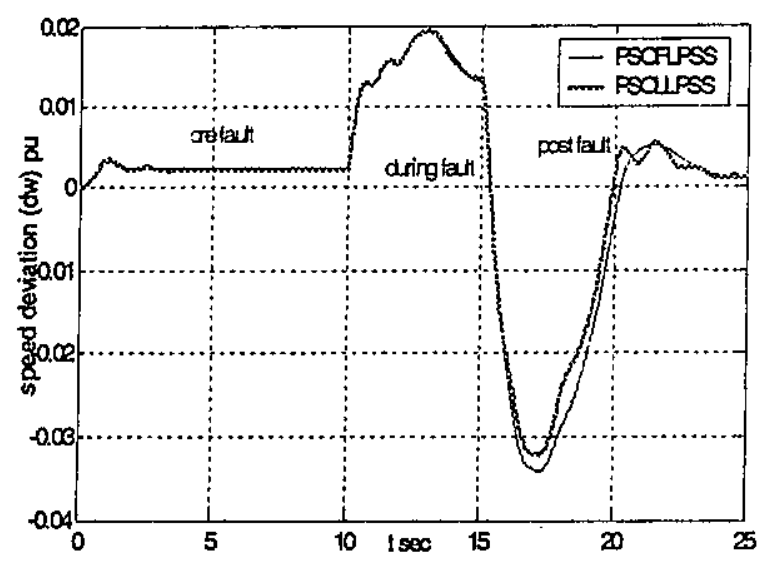

Fig. 15 comparison between PSOLLPSS and PSOFLPSS of machine (1) for a three phase-toground fault 


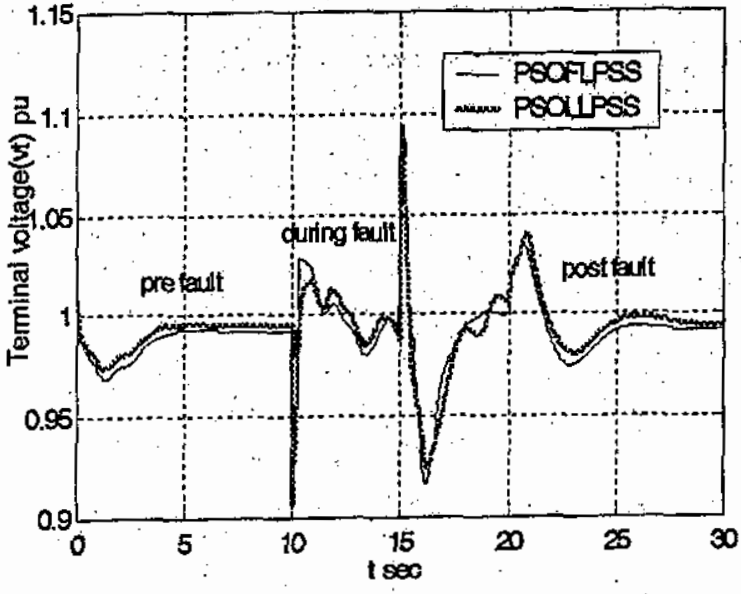

Fig. 16 comparison between PSOLLPSS and PSOFLPSS in machine (1) for a three phase-toground fault

\section{Line out of service}

The speed deviation $(\Delta \omega)$ time response of PSOLLPSS is better than response PSOFLPSS (less under shoot and settling time) as shown in the Fig.(17). The time response of terminal voltage (Vt) of PSOLLPSS is better than PSOFLPSS settling time and under shoot nearly the same as show in the Fig. (18).

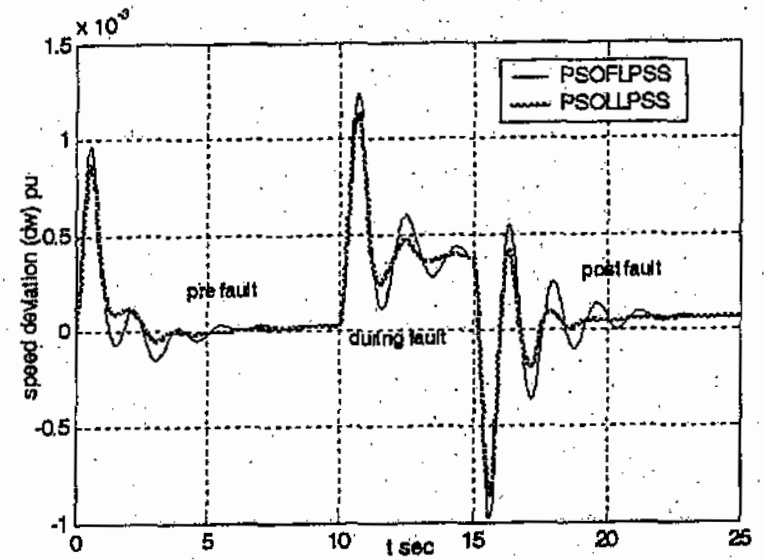

Fig. 17 comparison between PSOLLPSS and PSOFLPSS of machine (1) for a one line out of service

\section{E. load change $(+20 \%)$}

The speed deviation $(\Delta \omega)$ time response of the PSOLLPSS is better than PSOFLPSS (less over shoot, time settling) as show in the Fig (19). The time response of terminal voltage (Vt) of PSOFLPSS is better than PSOLLPSS less settling time and over shoot nearly the same as show in the Fig (20). A comparative study between the time response parameters for post fault condition using PSOFLPSS and PSOFLPSS have been made in Table (6).

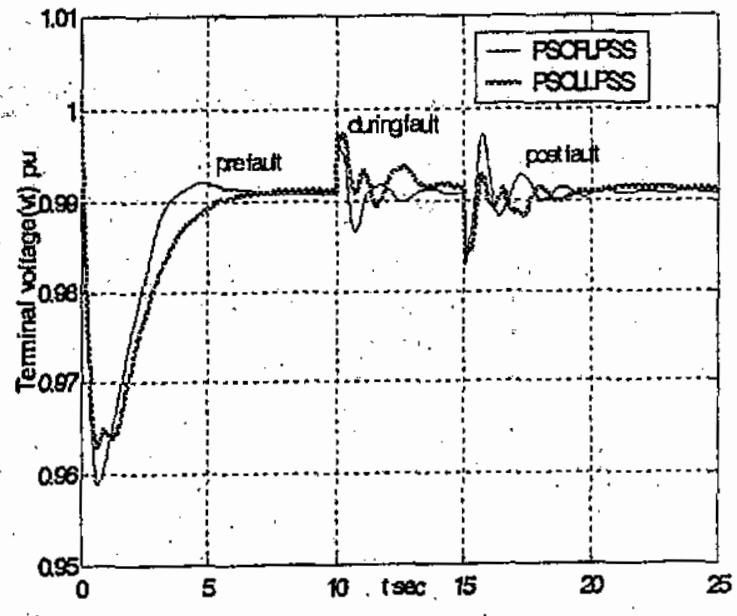

Fig. 18 comparison between PSOLLPSS and PSOFLPSS of machine (1) for a one line out of service

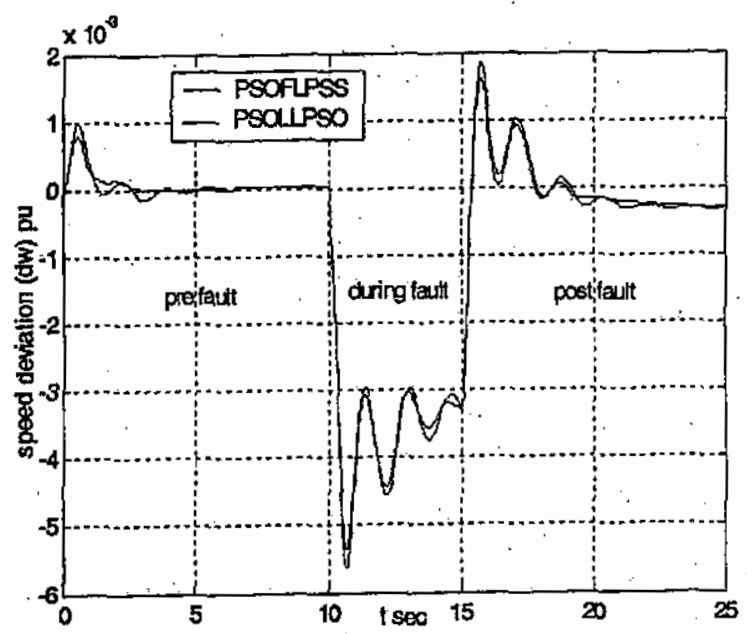

Fig. 19 comparison between PSOLLPSS and PSOFLPSS of machine (1) for a load change (20\%) at nominal loading)

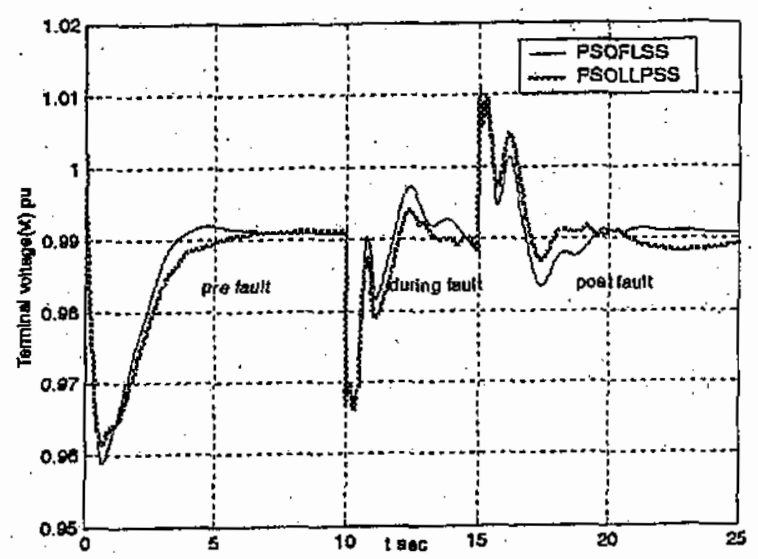

Fig. 20 comparison between PSOPSS and PSOFLPSS of machine (1) for a load change (20\%) at nominal loading 
Table (6) time response parameters for post fault condition using PSOFLPSS and PSOFLPSS

\begin{tabular}{|c|c|c|c|c|c|c|}
\hline Fault Types & Type of response & PSOPSS Tyes & $\begin{array}{l}\text { Max. Over shoot } \\
\text { in (pu) }\end{array}$ & $\begin{array}{l}\text { Max.Under shoot } \\
\text { in (pu) }\end{array}$ & $\begin{array}{l}\text { Peak time in } \\
\text { (sec) }\end{array}$ & $\begin{array}{l}\text { Settling time in } \\
\text { (sec) }\end{array}$ \\
\hline \multirow{4}{*}{$\begin{array}{l}\text { 1-Single phase } \\
\text { fault }\end{array}$} & \multirow{2}{*}{$\begin{array}{l}\text { Speed response } \\
\text { Fig (II) }\end{array}$} & PSOLLPSS & $1.60^{*} \mathrm{e}-4$ & $-6.99^{*} \mathrm{e}-4$ & 0.42 & 3 \\
\hline & & PSOFLPSS & $2.38 * \mathrm{e}-4$ & $-7.81 * e-4$ & 0.45 & 5 \\
\hline & \multirow{2}{*}{$\begin{array}{l}\text { Terminal voltage } \\
\text { response Fig (12) }\end{array}$} & PSOLLPSS & $1.4^{*} \mathrm{e}-3$ & $-1.1 * e-3$ & 0.1 & 4 \\
\hline & & PSOFLPSS & $1.3 * \mathrm{e}-3$ & $-1 * e-3$ & .09 & 4 \\
\hline \multirow{4}{*}{$\begin{array}{l}\text { 2-Double } \\
\text { phase fault }\end{array}$} & \multirow{2}{*}{$\begin{array}{c}\text { Speed response } \\
\text { Fig (13) }\end{array}$} & PSOLLPSS & - & $-6.45^{*} e-3$ & 0.87 & 4.5 \\
\hline & & PSOFLPSS & $6 * e-4$ & $-7.25^{*} \mathrm{e}-3$ & 0.91 & 5.8 \\
\hline & \multirow{2}{*}{$\begin{array}{l}\text { Terminal voltage } \\
\text { response Fig (14) }\end{array}$} & PSOLLPSS & $4.3 * e-3$ & $-6.1 * e-3$ & 1.33 & 6.0 \\
\hline & & PSOFLPSS & $4.1 * e-3$ & $-5.7^{*} e-3$ & 1.33 & 6.0 \\
\hline \multirow{4}{*}{$\begin{array}{c}\text { 3-Three phase } \\
\text { fault }\end{array}$} & \multirow{2}{*}{$\begin{array}{l}\text { Speed response } \\
\text { Fig (15) }\end{array}$} & PSOLLPSS & $5.5^{*} \mathrm{e}-3$ & $-3.2 * \mathrm{e}-2$ & 2.2 & 8.5 \\
\hline & & PSOFLPSS & $5^{*} \mathrm{c}-3$ & $-3.4 * \mathrm{e}-2$ & 2.3 & 9.0 \\
\hline & \multirow{2}{*}{$\begin{array}{l}\text { Terminal voltage } \\
\text { response Fig (16) }\end{array}$} & PSOLIPSS & $4^{*} e-3$ & $-6.6^{*} \mathrm{e}-3$ & 0.1 & 10 \\
\hline & & PSOFLPSS & $6^{*} e-3$ & $-6.7^{*} e-3$ & 0.12 & 11 \\
\hline \multirow{4}{*}{$\begin{array}{l}\text { 4-Line out of } \\
\text { Service }\end{array}$} & \multirow{2}{*}{$\begin{array}{l}\text { Speed response } \\
\text { Fig (17) }\end{array}$} & PSOLLPSS & $4.1^{*} \mathrm{e}-4$ & $-8.5 * \mathrm{e}-3$ & 0.6 & 3 \\
\hline & & PSOFLPSS & $5.5^{*} e-4$ & $-9.8 * e-4$ & 0.6 & 7 \\
\hline & \multirow{2}{*}{$\begin{array}{l}\text { Terminal voltage } \\
\text { response Fig (18) }\end{array}$} & PSOLLPSS & $2 * \mathrm{e}-3$ & $-7^{*} e-3$ & 0.5 & 4.5 \\
\hline & & PSOFLPSS & $6^{*} e-3$ & $-8 * \mathrm{e}-2$ & 0.5 & 0.5 \\
\hline \multirow{4}{*}{$\begin{array}{c}\text { 5-load change } \\
(+20 \%)\end{array}$} & \multirow{2}{*}{$\begin{array}{l}\text { Speed response } \\
\text { Fig (19) }\end{array}$} & PSOLLPSS & $1.6^{*} \mathrm{e}-3$ & 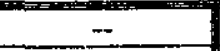 & 0.6 & 4.5 \\
\hline & & PSOFLPSS & $1.85 * \mathrm{e}-3$ & 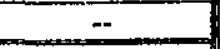 & 0.7 & 6.0 \\
\hline & \multirow{2}{*}{$\begin{array}{l}\text { Terminal voltage } \\
\text { response Fig (20) }\end{array}$} & PSOLLPSS & $1.8^{*} \mathrm{e}-3$ & $-1.9 * \mathrm{e}-3$ & 0.15 & 5.5 \\
\hline & & PSOFLPSS & $1.9 * \mathrm{e}-3$ & $-1.9 * \mathrm{e}-3$ & 0.15 & 4.5 \\
\hline
\end{tabular}

\section{CONCLUSION}

This paper presented a particle swarm optimization method (PSO) as a design method for determining the values of control parameters of the brushless exciter $(\mathrm{AClA})$, lead lag power system stabilizer (LLPSS) and fuzzy logic power system stabilizer (FLPSS). The problem of simultaneous and coordinated tuning of AClA exciter, LLPSS and FLPSS parameters of a single machine infinite bus power system was considered. This problem was formulated as an optimization problem, which was solved using particle swarm optimization technique. Simulation results showed the effectiveness of the proposed PSOLLPSS and PSOFLPSS to damp out the multi machine (interarea) modes of oscillations and work effectively over a wide range of loading conditions and fault conditions. Further-more, in multi machine system, the PSOLLPSS has given a good response in different types of fault conditions for the speed deviation time response and small difference between the PSOLLPSS and PSOFLPSS in the thermal voltage time response.

\section{REFERENCES}

[1] G. Cheng, Genetic Algorithms \& Engineering Design. New York: Wiley, 1997.

[2] P.M. Anderson and A. A. Fouad, Power System Dynamics and Stability. Ames, IA:Iowa State Univ. Press, 1977.
[3] P. W. Sauer and M. A. Pai, Power System Dynamics and Stability. Englewood Cliffs, NJ: Prentice-Hall, 1998.

[4] F.P.deMello and C.Concordia, "Concepts of synchronous machine stability as affected by excitation control", IEEE Trans, Power App. Syst,,vol. PAS-88,pp.316-329.1969.

[5] M.J.Gibbard, N.Martins; et al., "Recent Applications of Linear Analysis Techniques",IEEE Trans.Power Syst., vol. 16, NO.1pp. 154-162,Feb. 2001.

[6] P. Kundur. Power system control and stability, new york: McGraw-Hill, Inc., 1994.

[7] Amany EL-Zonkoly, "Optimal Tuning OF Power Systems Stabilizers and AVR Gains Using Particle Swarm Optimization" journal of Expert systems with Applications, Elsevierltd., vol.31, NO.939, PP.551-557,2006.

[8] A.J.Urdaneta, N.J.Bacalao; et al., "Tuning of Power System Stabilizers Using Optimization Techniques," IEEE Trans. Power Syst., vol. 6, No. 1, pp. 127-134, Feb.1991.

[9] A.Feliachi, X.Zhang; et al., "Power System Stabilizers Design Using Optimal Reduced Order Models Part II: Design", IEEE Trans. Power Syst., vol .3, no.4,pp. 16761684,nOv.1988. 
[10] D.Xia and G. T. Heydt, "Self-tuning controller for generator excitation control", IEEE Trans.power APP. Syst, pp. 1877-1885, 1983.

[11]S.Abe and a. DOI, "A new power system stabilizer

[12] synthesis in multi-machine power systems", IEEE Trans. Power App. Syst., vol.PAS-102, PP. 3910-3918,1983.

[13] J.M.Arredondo, "Results of a study on location and tuning of power system stabilizers", Int. journal. Electr. Power energy Syst.,vol.19,pp. 563-567, 1997 .

[14]A.L.B.do Bmfim, G.N.Taranto; et al., "Simultaneous Tuning of Power System Damping Controllers Using Genetic Algorithms", IEEE . Trans. Power Syst.,vol.15,NO.1,pp. 163-169,Feb.2000.
[15]J.Kennedy and R.Eberhart; "Particle swarm optimization," in proc. IEEE Int. Conf. Neural Networks, vol.IV, Perth, Australia,1995,pp.1942-1948.

[16]Y.Shi and R.Eberhart, "Amodified particle swarm optimizer", in proc. IEEE Int. Conf.Evol. Comput., Anchorage, ak, may 1998, pp.69-73.

[17]H.Yoshida,K.Kawata, and Y.Fukuyama, "A particle swarm optimization for reactive power and voltage control considering voltage security assessment", IEEE Trans. Power Syst.,vol.15,pp. 1232-1239, Nov. 2000.

[18]1.j.Cai and I.Erlich, "Simultaneous Coordinated Tuning of PSS and FACTS Damping Controllers in LARGE Power System", IEEE Trans. Power Syst.; vol.20, No. 1 pp. 294300,FEB. 2005 .

[19]Mohamed E.EL-Hawary, Electric Power Applications of Fuzzy Systems, IEEE,(1998). 